\title{
Contrastive Analysis and Reflection on Higher Education between China and Germany
}

\author{
Zhilin Liu, a, ,, Qidan Zhu ${ }^{1}$, Li Su ${ }^{1}$, Xin Yuan ${ }^{1}$ \\ ${ }^{1}$ College of Automation, Harbin Engineering University, Harbin, China \\ aliuzhilin@hrbeu.edu.cn \\ ${ }^{*}$ Corresponding author
}

Keywords: Contrastive analysis, China, Future development trend, Germany, Higher education.

\begin{abstract}
With the urgent requirement of the rapid development of higher engineering education in our country and the reality of college expansion, the problems related to the reformation of the education management system in colleges and universities need to be solved. In this paper, represented by Duisburg-Essen University, the academic level of German higher education and the ability of engineering capacity-building, school-running characteristics, and internationalization trends have been introduced, then the methods of teaching and practicing for German higher education have been learned together with the future development direction. In the comparative analysis with China, the aspects that can be used in the current reformation of Chinese higher education management system have been pointed out.
\end{abstract}

\section{中德高等教育对比分析与思考 \\ 刘志林 ${ }^{1, a}{ }^{*}{ }^{*}$, 朱齐丹 ${ }^{1}$, 苏丽 ${ }^{1}$, 原新 ${ }^{1}$ \\ 1哈尔滨工程大学自动化学院, 哈尔滨, 中国 \\ aliuzhilin@hrbeu.edu.cn \\ *通讯作者}

关键词: 对比分析; 中国; 未来发展趋势; 德国; 高等教育

中文摘要. 伴随着我国高等工程教育快速发展的迫切要求以及高校扩招的现实情况, 高校教 育管理体制改革的相关问题丞待解决。本文介绍了以杜伊斯堡艾森大学为代表的德国高等教 育学术水平和工程能力培养政策、办学特色以及国际化趋势, 从中了解到德国高等教育进行 教学和实践的方法以及未来的发展方向, 并在与我国的对比分析中, 指出在我国目前高等教 育管理体制改革中能够借鉴的方面。

\section{1. 引言}

目前, 我国正在大力发展高等教育, 随着不断增长的学校规模, 如何更好地进行教育管 理体制改革来保证高等教育更加良好地发展是一个值得深思的问题 ${ }^{[1-3]}$ 。结合2014-2015年间 对德国杜伊斯堡艾森大学进行学术访问的观感, 发现两国高等工科教育与其经济发展、学校 和企业界的联系以及国际市场占有存在着密切的关系。中德两国高等工科人才的培养目标有 着大体相当的要求,但其实施步骤又分别适合各自国情。与中国的大学相比, 德国大学具有很 多不同于我国大学教育制度的特色体制和文化, 其中许多既特色鲜明又符合德国国情的教育 制度和理念很值得我们学习和思考 ${ }^{[4]}$ 。本文就我国和以杜伊斯堡艾森大学为代表的德国高等 
教育体系, 在学术水平和工程能力培养政策、办学特色以及国际化趋势等方面进行分析与思 考。

\section{2. 学术水平培养}

\section{1 国际前沿的课堂教学}

杜伊斯堡艾森大学是一所德国综合性公立大学，坐落在德国西部北莱茵威斯特法伦州， 2003年由其前身杜伊斯堡大学和埃森大学合并而成, 是德国最大的十所大学之一, 也是通过 中国教育部留学认证的德国国立大学。杜伊斯堡艾森大学的研究生教育, 从教学过程、课后 作业, 直至最终提交研究报告, 都是以期刊论文的撰写模式来要求学生; 课堂教学过程中将 目前许多国际顶级学术杂志所发表的研究成果引入到教案中。以本人访学的杜伊斯堡艾森大 学控制科学与工程系为例, 鲁棒控制课程的研究生教学直接将IFAC (国际自动控制联合会) 的学术论文集作为研究生的课外辅导资料。经过与国际最前沿学术论文的同步跟踪, 使得学 生了解目前所学课程国际上处于什么水平, 为后续实践教学和人才的继续深造, 打下良好学 术基础。

\section{2 制度化的学术讨论}

杜伊斯堡艾森大学是一所国际化的大学, 各国高水平研究学者访问频繁。学校各个教学 楼和实验室的电子公告牌每天都会实时滚动公告各种学术报告的题目、主讲人以及报告内容。 每个学生的注册邮箱也会定期接到学术报告通知, 学校对研究生以上的学生明确要求参加相 关领域的学术报告, 并且组织会后的学术讨论。经过长时间的发展, 学校形成了这种研究生 定期向导师汇报学术进展的学术气氛。这不仅便于老师掌握学生的学习动向, 而且有利于培 养学生的国际交流能力。反观国内高校, 很多学术报告缺少学生的参与, 无论是老师还是学 生对学术报告都不太重视。

\section{3. 工程能力培养}

\section{1 紧密的校企联合}

杜伊斯堡艾森大学 (尤其是工科专业) 一直将培养具有实际动手能力的工程技术人才作 为人才培养的主要目标, 不断提高学生科研支持力度。以控制工程系为例, 对于思维活跃、 创造力十足的潜在拔尖人才, 学校会尽力为他们的兴趣服务, 提供所有可能提供的一切实验 室资源和科研项目支持, 以满足其旺盛的知识需求 ${ }^{[5]}$ 。就这一点, 国内目仍存在差距, 国内 目前对学生工程经验和科研能力的培养大多还局限于参与综合性实验和创新性实验的层面, 支持学生进行科学研究的力度相对不足, 学生 (尤其是本科生) 参与具体实际科研项目的机 会较少, 甚至一些研究生也只是进行一些脱离实际的理论研究。只有让学生较多的参与企业 实际工程项目，才能在学习的过程中加深对企业的了解，为未来的发展奠定基础。

\section{2 定期的参观学习}

德国大学会定期组织参观, 大多数由学校和企业联合发出, 学校或者企业负责提供学生 的交通和简单午餐。学校通过这种形式扩大学生的视野, 而对企业来说则是一次很好的宣传, 对后期人才的招聘起到积极的作用 ${ }^{[6]}$ 。德国的工科大学，大多数地处工业发达地区，国际化 的跨国大公司鳞次栉比, 向高等院校开放是德国企业文化的一部分。而多与企业交流, 也是 德国大学的传统。在德国大学里某些应用性较强的专业, 学生根据自己的专业要求选择相关 必修课程, 学校通常与企业长期建立合作关系, 并且专门设有一个学期的实习期为学生提供 专业实习的平台。 


\section{3 校企的职责分离}

德国高校与企业虽然紧密结合，但各自的职责又很明晰。高校负责研发，企业负责生产， 学校和企业的紧密结合最终形成研究与生产的无缝连接。德国高校所从事的科研项目的一个 显著特点, 就是将生产环节剥离, 即对企业的需求提供指导, 较多承担基础性研究, 生产交 给企业去完成, 各自发挥各自的优势。

\section{4. 特色办学}

\section{1 全面的导师负责制}

杜伊斯堡艾森大学无论是研究生的入学, 还是毕业, 都是以导师全面负责, 没有统一的 入学考试和硬性的毕业标准, 一切以导师对学生的认可度来决定学生是否具备毕业答辩的资 格。这种全面的导师负责制, 是与德国注重个人诚信的国情息息相关的。德国一名大学教授 的社会地位极高, 教授的推荐信和证明信相当于一份及有效力的公证件。德国政府在薪金和 税收方面也向高校教师极大的倾斜。在高福利高税收的德国, 种种有益的政策和环境对大学 教师有很强的吸引力, 这也是德国重视高等教育的一个体现。德国大学教授也充分尊重社会 给予的崇高地位和信任, 在考核学生的入学或毕业资格的过程中始终保证着严谨。德国的学 术腐败极少发生，这种全面的导师负责制是德国社会文化的产物，也符合德国的基本国情。

\section{2 多样的课程设置和评价方式}

德国的高校课程设置根据不同的大学类型和不同的专业而定, 并有相关的英文课程。大 学里可供学生选择的选修课很多, 学生可根据自己的爱好选择更多广泛的课程。在课程评价 方面, 德国大学教师授课时没有固定的教材和严格的考勤制度, 课堂以学生为主体, 教师重 在引导学生的思维方向和创新能力。学生的课堂表现、中期展示和笔试成绩决定学生一个学 期的表现。对学分的认定包括课上课下两方面的投入时长。此种灵活的授课方式和多样化的 课程评价体系可以作为我国高等教育改革的借鉴。

\section{3 完全免费的义务教育}

德国的高等教育机构一般分成三类:（1）传统的综合性大学包括大学和工业大学，如斯 图加特大学, 杜伊斯堡艾森大学, 慕尼黑工大; (2) 应用科技大学, 也称为高等职业技术学 院;（3）培养艺术和音乐类人才的艺术学院等高等专科学校。在德国, 从小学到大学, 国家都 实行免费义务教育, 并且不需要进行类似于我国高考的入学考试来获得入学资格, 而是根据 学习情况和学生意愿决定在大学或者职业学校完成学业。

\section{5. 国际化发展趋势}

\section{1 跨境的学分互认和学位互授}

欧洲学分互认体系（European Credit Transfer System，ECTS）是欧洲诸国间在高等教育 领域互相衔接的一个项目, 以确保各国高等教育标准相当。1999年欧洲29个国家在意大利的 博洛尼亚大学签订的博洛尼亚宣言该体系对所有愿意参加的欧洲国家开放。根据该体系, 一 学年相当于60 ECTS学分, 对应1500-1800小时学习, 不论国家和教育质量、教育等级, 以便 在联盟范围内转换学分。目前, ECTS和国内的学还分没有统一的转换方式。一般情况下, 国 内的一个学分可以换 1.5 到 2.5 个ECTS。

\section{2 大比重的留学生和外籍教师}

教师队伍国际化是高等教育国际化的一个重要标志 ${ }^{[7-8]}$ 。据最新统计, 德国的大学教师中 大约 $20 \%$ 是外籍人士。甚至在一些世界知名的大学的教师和研究人员中, 外籍人士高达 $40 \%$ 。 
在国际化的课程体系方面, 开设更多面向国际的课程, 许多课程都提供英文授课来吸引更多 的外国留学生。德国的高校非常重视学生来源的国际化。据统计, 2011年, 在德外国学生人 数为 24 万余人, 外国学生人数占德国高校学生总人数的 $11.8 \%$, 遍布世界各地。其中欧洲和亚 洲学生人数增速最快。需要特别指出的是德国高校 $1 / 3$ 的本科生课程需要学生出国留学, 属于 强制项要求。在读研究生中, 外国学生约占 $40 \%$ 。

\section{6. 结束语}

高等教育是一个民族进步的灵魂, 是一个国家兴旺发达的不竭动力。培养综合素质高、 创新能力强的人才, 是现代大学的历史使命, 是建设人力资源强国的迫切要求, 也是高水平 研究型大学教育质量的重要标志。通过在德国一年的学习和生活, 深深感受到中德大学从办 学理念、管理模式和评价体系等各方面, 都存在巨大的差异。结合我国的国情, 研究我国高等 教育的人才培养目标、途径及改革取向, 这是需要进行广泛调研、认真思考、通过不断探索和 实践来加以回答的重大课题。

\section{致谢}

本文为哈尔滨工程大学教学改革研究项目《基于德式教学理念的研究生培养模式改革研 究》(JG10217Y13), 《基于 “理论引导-兴趣提升-科研实践” 的机器人课程教学模式改革研 究》(JG2016BZD08), 《发挥专业优势的创新创业人才培养模式研究与实践》, 《国际化视 野下研究生创新人才培养探索与实践》(JG10217Y10)的阶段性成果之一。

\section{References}

[1] Y. Li, W. Hu, Q. Shi, and L. Huang, Research no the path to Shanxi higher education internationalization-based on comparative analysis of Chinese and German higher education, Journal of Xi'an Polytechnic University, vol.29, no.4, pp. 508-512, 2015.

[2] W. Song, Research on higher education system between Germany and China, Journal of Guangdong Industry Technical College, vol.4, no.3, pp.41-44, 2005.

[3] S. Tan and W. Xie, Research on educational reform and institutional innovation, Educational Research, vol.7, pp. 45-50, 2010.

[4] Y. Guo, German education's implications on national education in China, Journal of Heilongjiang Institute of Socialism, vol.3, pp.61-64, 2013.

[5] P. Gwynne, International careers report: Germany-in pursuit of excellence, Higher Education, vol.310, no.1, pp. 129-132, 2005.

[6] S. Schindler and D. Reimer, Differentiation and social selectivity in German higher education, High Education, vol.61, no.3, pp. 261-275, 2011.

[7] X. Zhu, International trend of education internationalization, World Education Information, vol.17, pp. 60-67, 2014.

[8] J. Wu, Research on current development of German higher education internationalization, Beijing: Beijing People's Press, vol.9, pp. 135-136, 2009. 